Nanostructured Energetic Materials with Sol-Gel Methods

A. Gash, J. Satcher, R. Simpson, B. Clapsaddle

November 26, 2003

Materials Research Society Fall 2003 Meeting Boston, MA, United States

December 1, 2003 through December 5, 2003 
This document was prepared as an account of work sponsored by an agency of the United States Government. Neither the United States Government nor the University of California nor any of their employees, makes any warranty, express or implied, or assumes any legal liability or responsibility for the accuracy, completeness, or usefulness of any information, apparatus, product, or process disclosed, or represents that its use would not infringe privately owned rights. Reference herein to any specific commercial product, process, or service by trade name, trademark, manufacturer, or otherwise, does not necessarily constitute or imply its endorsement, recommendation, or favoring by the United States Government or the University of California. The views and opinions of authors expressed herein do not necessarily state or reflect those of the United States Government or the University of California, and shall not be used for advertising or product endorsement purposes. 


\title{
Nanostructured Energetic Materials with Sol-gel Methods
}

\author{
Alexander E. Gash*, Joe H. Satcher Jr., Randall L. Simpson, Brady J. Clapsaddle \\ Energetic Materials Center \\ Lawrence Livermore National Laboratory \\ Livermore, CA 94551
}

UCRL-PROC-201186

\begin{abstract}
The utilization of sol-gel chemical methodology to prepare nanostructured energetic materials as well as the concepts of nanoenergetics is described. The preparation and characterization of two totally different compositions is detailed. In one example, nanostructured aerogel and xerogel composites of sol-gel iron (III) oxide and ultra fine grained aluminum (UFG Al) are prepared, characterized, and compared to a conventional micron-sized $\mathrm{Fe}_{2} \mathrm{O}_{3} / \mathrm{Al}$ thermite. The exquisite degree of mixing and intimate nanostructuring of this material is illustrated using transmission and scanning electron microscopies (TEM and SEM). The nanocomposite material has markedly different energy release (burn rate) and thermal properties compared to the conventional composite, results of which will be discussed. Small-scale safety characterization was performed aerogels and xerogels of the nanostructured thermite. The second nanostructured energetic material consists of a nanostructured hydrocarbon resin fuel network with fine ammonium perchlorate $\left(\mathrm{NH}_{4} \mathrm{ClO}_{4}\right)$ oxidizer present.
\end{abstract}

\section{Introduction and Background}

Since the invention of black powder, one thousand years ago, the technology for making solid energetic materials has remained either the physical mixing of solid oxidizers and fuels (e.g. black powder), or the incorporation of oxidizing and fuel moieties into one molecule (e.g., trinitrotoluene (TNT)). The basic distinctions between these energetic composites and monomolecular energetic materials are well illustrated with a comparison of their respective kinetic and thermodynamic properties. In composite systems, desired energy properties can be attained through readily varied ratios of oxidizer and fuels. A complete balance between the oxidizer and fuel may be reached to maximize energy density. However, due to the granular nature of composite energetic materials, the reaction kinetics are, by comparison, slow as they are controlled by mass and thermal transport rates between micron or millimeter-sized reactants.

Conversely in monomolecular energetic materials, the rate of energy release is primarily controlled by chemical kinetics, and not by mass transport. Therefore, monomolecular materials can have much greater power than composites. However, a major limitation with these types of materials is the total energy density achievable through CHNO chemistry. Currently, the highest energy density for monomolecular materials is about half that achievable in composite systems.

* Corresponding author contact information: LLNL, P.O. Box 808 L-092, Livermore, CA 94551 gash2@1lnl.gov; Ph. (925) 423-8618 
A comparison of the energy densities of selected monomolecular and composite systems is shown in Figure 1. [1,2]

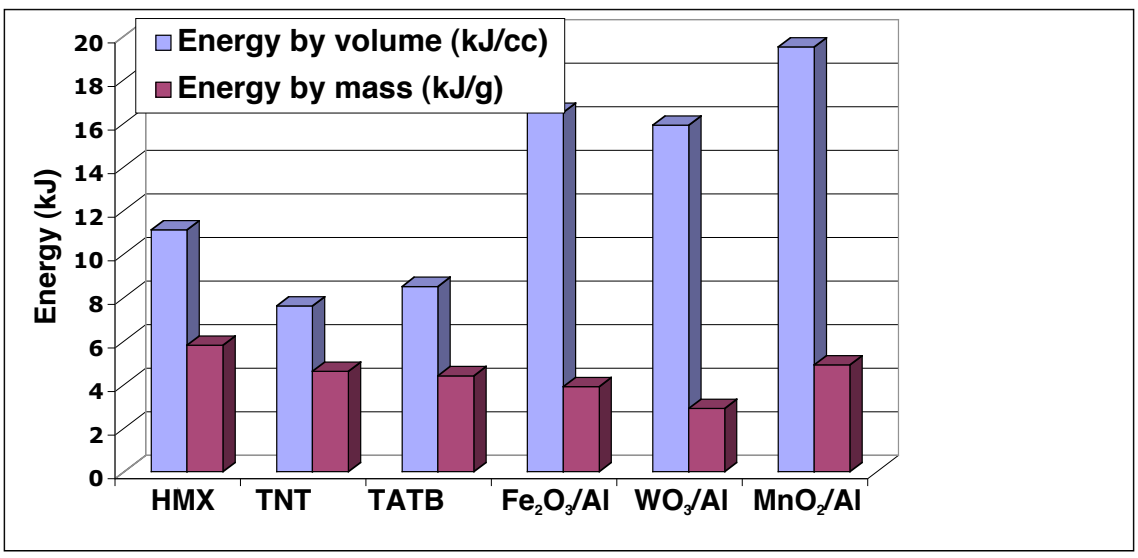

Figure 1. Energy and energy density values for some monomolecular (HMX, TNT, TATB) and composite energetic materials.

It is obvious that materials with a combination of the excellent thermodynamics of composites with the rapid kinetics of monomolecular materials would be very desirable for a number of applications.

One potential approach to this challenge is straightforward: decrease the particle size of the constituent phases in composite energetic materials. This serves to increase the surface area of the materials, which afford increased contact area between fuel and oxidizer. This results in a much larger fraction of the composite that can react instantaneously. The effective downsizing of particles also permits more intimate mixing of phases and reduces the diffusion distances between them. Both experimental and theoretical efforts by Brown et al. and Sukai et al. indicate that a decrease in particle size resulted in a qualitative increase in burn rates in solid-solid mixtures of oxidizers and fuels. $[3,4]$

Current science and technology advances in the area of nanomaterials afford the energetic materials community a means to address this challenge. A remarkable increase in contact area is possible with nanomaterials and lead to energetic nanocomposites with new and sometimes exceptional properties. By reducing the diffusion distances the mass and thermal transport problems that conventional energetic composites suffer from are mitigated. Using this approach the energy release rates of nanocomposite energetic materials may approach those of monomolecular materials. Already Son and co-workers at Los Alamos National Laboratory have shown that pyrotechnic nanocomposites of $\mathrm{MoO}_{3}$ and $\mathrm{Al}$ burn at extremely rapid rates $(>100 \mathrm{~m} / \mathrm{s}) .[5]$ Nearly two orders of magnitude higher than conventional composites! Even more appealing, is the prospect of being able to potentially tailor energy release rates of these materials to fit a particular application. In addition, it is well known that the initiation, energy release, and safety properties of energetic materials are highly dependent on particle size and morphology. Therefore it is certain that energetic nanocomposites will have very interesting properties. Taking all of the potential benefits into account, research in this area has become widespread. 
It is our contention that for energetic nanomaterials to have a significant impact in the area of energetic materials, processes for their synthesis must satisfy significant production specifications such as cost, health and safety, and reproducibility. There exist numerous physical and chemical synthesis and processing routes (e.g., vapor condensation methods, sol-gel micellular, sonochemical, sonication, and ball milling) to prepare nanomaterials of both oxidizers and fuels.[6] Each method has its own set of benefits and drawbacks. At LLNL we have been actively investigating the application of sol-gel methodology to the preparation of entirely unique energetic nanocomposites. We feel that the sol-gel method is an approach to nanomaterials synthesis for energetic nanocomposites that will satisfy many of the specifications.

There are a number of excellent books and review articles on sol-gel methodology.[7,8] For that reason this production will not discuss more than the basics. The scheme presented in Figure 2 summarizes the process.

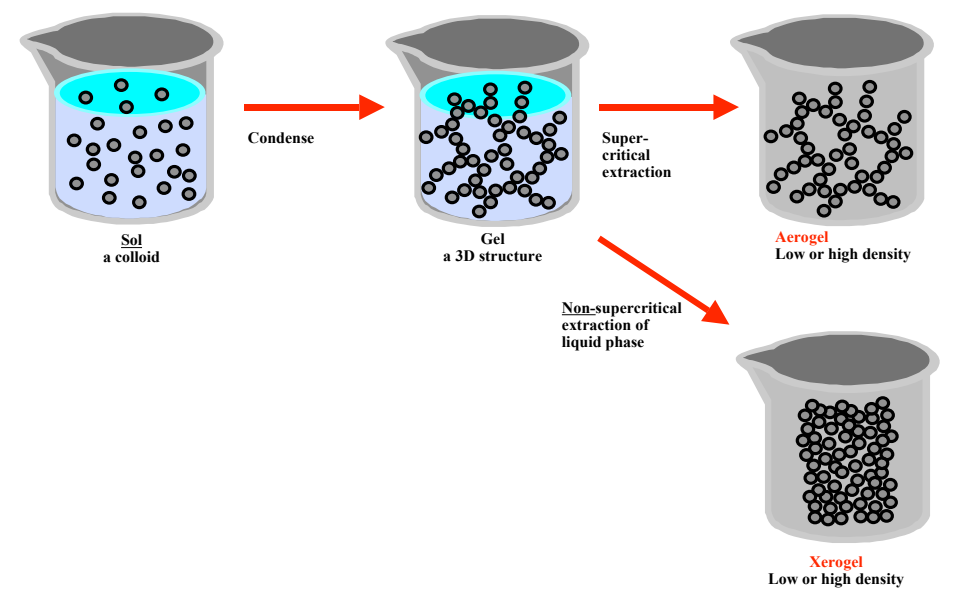

Figure 2. Scheme showing the basic sol-gel process.

In summary, molecular precursors are induced to undergo hydrolysis and condensation in solution to form a sol. Subsequent manipulation can lead to cross-linking of the sol particles to form a gel whose particles and pore sizes have dimensions on the order or 5-50 $\mathrm{nm}$. Processing of the gel to a dry solid provides the basic distinction between aerogels (dried supercritically) and xerogels (dried without supercritical fluid). In general, aerogels have lower densities, higher porosities, and higher surface areas than xerogels, but both materials contain a architecture of interconnected particles and pores with nanoscopic dimensions.

The appeal of the sol-gel approach to energetic materials is that it offers the possibility to precisely control the composition, density, morphology, and particle size of the target material at the nanometer scale. An added feature is near or ambient temperature gelation and low temperature drying schemes prevent degradation of the energetic molecules. In addition the numerous processing options allow the fabrication of powders, porous monoliths, dense parts, coatings and thin films. The method presented here allows more than the simple mixture of two nanophases. The process forms a porous three-dimensional structured network of nanoparticles whose cavities can be partially filled with the complementary oxidizer or fuel. A schematic of the sol-gel nanostructured energetic materials is shown in Figure 3. 


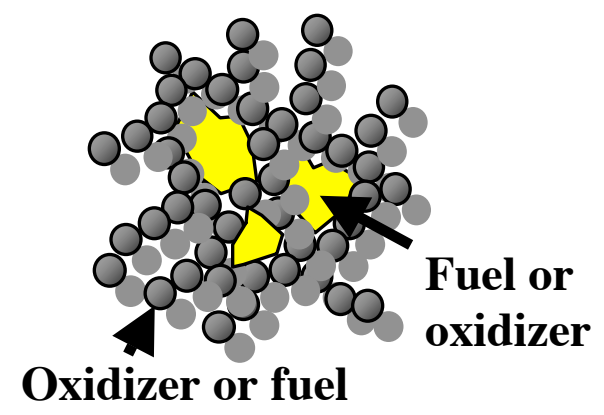

Figure 3. Idealized representation of sol-gel nanostructured energetic material.

The nanostructuring of the composite performs two unique functions relative to simple mixing of nanopowders. First, it provides very intimate mixing of the phases as the sol-gel phase is formed in situ, in a colloid of the added particulate phase, and it grows around the suspended particles. This methodology promotes very intimate mixing of oxidizer and fuel. Second, it provides a three-dimensional nanostructure where the two phases are interlocked and will resist separation upon manipulation and have different properties relative to mixtures of nanopowders.[9-11]

The method is very versatile as the composition of the sol-gel nanostructured material can be readily varied to give the resulting material varied properties. For example the skeletal sol-gel matrix in Figure 3 can be made up of oxidizer (e.g., $\mathrm{Fe}_{2} \mathrm{O}_{3}, \mathrm{WO}_{3}, \mathrm{SnO}_{2}$ ) or fuel (e.g., hydrocarbon resin or carbon) and the imbedded particulate phase maybe fuel (Al) or oxidizer (e.g., $\mathrm{NH}_{4} \mathrm{ClO}_{4}$ ). In the metal oxide/Al systems the primary output would be heat and light whereas the organic sol-gel nanostructured material would generate gas upon reaction. The compositional versatility of this approach may lead to applications in a wide range of areas. The unique compositional and processing properties of sol-gel nanostructured energetics make it and attractive technology for new applications of energetic materials. For example, the method may be amenable to creating energetic coatings on wafers or on Microelectromechanical (MEMS) devices.

\section{Experimental}

Preparation of $\mathrm{Fe}_{x} \mathrm{O}_{y} / \mathrm{Al}(\mathrm{s})$ pyrotechnic nanocomposites. To prepare a $\mathrm{Fe}_{2} \mathrm{O}_{3} / \mathrm{Al}(s)$ pyrotechnic nanocomposite a $\mathrm{Fe}_{2} \mathrm{O}_{3}$ sol was generated and carefully monitored using a synthetic approach reported elsewhere.[12,13] In a separate vessel ultrafine grain aluminum was suspended in ethanol and sonicated for 15 minutes. Near the gelation point of the $\mathrm{Fe}_{2} \mathrm{O}_{3}$ sol the UFG Al was added and the composite mixture geled soon after. Samples prepared by this method were subjected to the same drying conditions as described above for processing to aerogels or to xerogel monoliths.

Safety characterization. Small scale testing of energetic materials and other compounds is done to determine their sensitivity to various stimuli including thermal degradation, friction impact and static spark. We performed tests such as Thermal Analysis, Drop Hammer (Impact Sensitivity), Friction, and Spark. These tests are of monumental importance for several reasons, 
but mainly to outline parameters for the safety in handling and carrying out experiments, and storage.

The sensitivity these materials toward electrostatic discharge was measured on a modified Electrical Instrument Services electrostatic discharge tester. Samples were loaded into Teflon washers and covered with a $1 \mathrm{~mm}$ thick Mylar tape. The sensitivity is defined as the highest energy setting at which 10 consecutive "no-go" results are obtained using a $10 \mathrm{kV}$ potential. The frictional sensitivity of the sol-gel nanostructured energetic materials was evaluated using a B.A.M. high friction sensitivity tester. The tester employs a fixed porcelain pin and a movable porcelain plate that executes a reciprocating motion. Weight affixed to a torsion arm allows for a variation in applied force between 0.5 and $36.0 \mathrm{~kg}$. The relative measure of the frictional sensitivity of a material is based upon the largest pin load at which less than two ignitions (events) occur in ten trials.

An Explosives Research Laboratory Type 12 Drop Weight apparatus, more commonly called a "Drop-Hammer Machine" was used to determine the impact sensitivity of these materials relative to the primary calibrants PETN, RDX, and Comp B-3. The apparatus was equipped with a Type 12A tool and a $2.5 \mathrm{~kg}$ weight. In the test a $35 \mathrm{mg}$ sample was impacted on a Carborundum "fine" (120-grit) flint paper. A "go" was defined as a microphone response of $1.3 \mathrm{~V}$ or more as measured by a model 415B Digital Peakmeter. The mean height for "go" events, called the "50\% Impact Height" or $\mathrm{DH}_{50}$, was determined using the Bruceton up-down method. The $\mathrm{DH}_{50}$ of PETN, RDX, and Comp B-3 calibrants were measured at $15.5 \mathrm{~cm}, 34.5$ $\mathrm{cm}$, and $41.4 \mathrm{~cm}$, respectively.

Preparation of resorcinol/formaldehyde/ammonium perchlorate energetic nanocomposites. Using a sol-gel procedure first described by Pekala to make aerogels, a porous organic solid matrix was prepared by the polycondensation of resorcinol with formaldehyde (RF) using $\mathrm{Na}_{2} \mathrm{CO}_{3}$ as a catalyst.[14] Subsequent crystallization of an oxidizer, ammonium perchlorate (AP), within the pores of the gel matrix, completes the synthesis. The oxidizer was first dissolved in water, and then added to the reacting RF sol prior to gelation. Gelation of the RF sol occurred first. Crystallization of the AP was then induced by exchanging the liquid residing in the pores for a solvent in which the oxidizer was insoluble. The final step of removing the pore fluid was done by slow evaporation resulting in a dense solid.

Processing of iron (III) oxide gels. The wet gels were covered and allowed to age for at least 24 hours under ambient conditions. After that they were immersed in a bath of absolute ethanol where they were washed for $\sim 1$ week. Aerogel samples were processed in Polaron ${ }^{\mathrm{TM}}$ supercritical point drier. The solvent liquid in the wet gel pores was exchanged for $\mathrm{CO}_{2}(l)$ for 23 days, after which the temperature of the vessel was ramped up to $\sim 45^{\circ} \mathrm{C}$, while maintaining a pressure of $\sim 100$ bars. The vessel was then depressurized at a rate of about 7 bars per hour. (CAUTION: Take special care when doing supercritical drying of energetic composites. We used only $\mathrm{CO}_{2}$ (low temperature $\sim 45^{\circ} \mathrm{C}$ ) supercritical extraction and place a blast shield in front of the extraction vessel.)

Physical characterization. Surface area analysis was performed using an ASAP 2000 Surface area Analyzer (Micromeritics Instrument Corporation) with resulting data analyzed by BET (Brunauer-Emmett-Teller) methods. Samples of aerogel $(0.1-0.2 \mathrm{~g})$ were heated to 200 ${ }^{\circ} \mathrm{C}$ under vacuum $\left(10^{-5}\right.$ Torr $)$ for at least 24 hours to remove all adsorbed species. Nitrogen 
adsorption data was taken at five relative pressures from 0.05 to 0.20 at $77 \mathrm{~K}$, to calculate the surface area by BET theory. The high-resolution transmission electron microscopy (HRTEM) was performed on a Philips CM300FEG operating at $300 \mathrm{keV}$ using zero loss energy filtering with a Gatan energy Imaging Filter (GIF) to remove inelastic scattering. The images where taken under bright field conditions and slightly defocused to increase contrast. The images were also recorded on a $2 \mathrm{k} \times 2 \mathrm{k}$ CCD camera attached to the GIF. Powdered samples were dispersed in methanol and drops of the resulting mixture were deposited onto a carbon coated $\mathrm{Cu}$ grid using a pipette. Scanning electron microscopy (SEM) was carried out using a Hitachi S-4500 cold field emission SEM. Typical accelerating voltages used for aerogel samples ranged from 1.8-6 kV and depended on sample conductivity. No sample preparation (i.e., coating with conductive layer of $\mathrm{Au}$ ) was performed on the samples.

\section{Results and Discussion}

We have developed sol-gel methods to prepare high surface area nanostructured iron (III) oxide materials. These materials can be made with high surface area $\left(\sim 250-350 \mathrm{~m}^{2} / \mathrm{g}\right)$, either crystalline or amorphous, and with reasonable purities using a simple one step chemical method. In addition, we have been able to selectively prepare nanometer-sized iron (III) oxide nanostructures with two distinctly different particle morphologies.[12,13] Figure 4 contains SEM images of two different morphological types, one with needle-like morphology and the
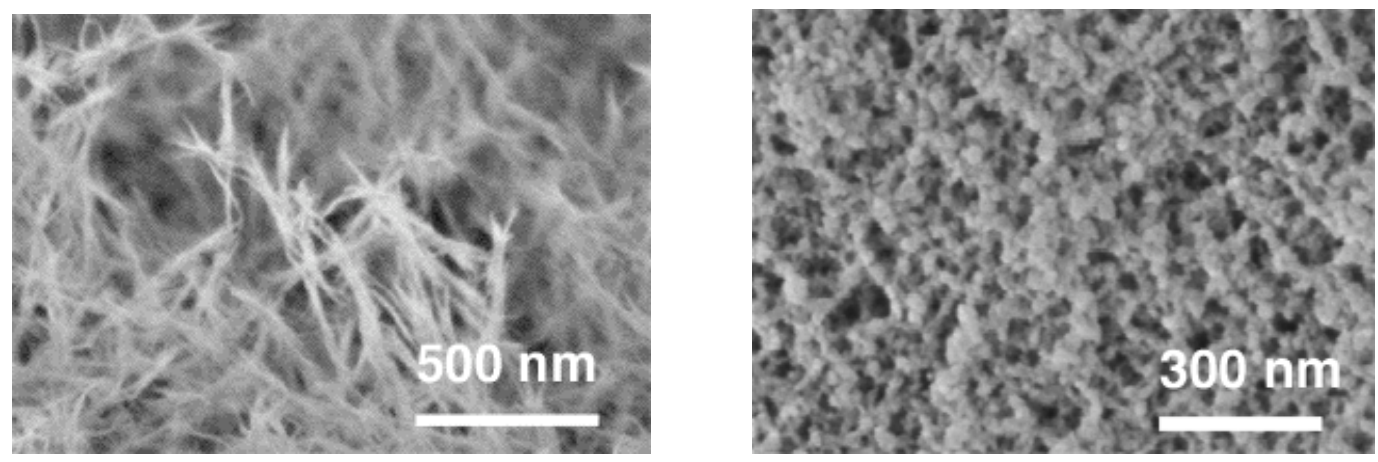

Figure 4. Scanning electron micrograph images of two iron (III) oxide sol-gel nanomaterials with markedly different particle morphologies.

other with particulate morphology. This is extremely useful as significant quantities of pure materials with uniform particle sizes and morphologies can be prepared reproducibly. It is very likely that sol-gel nanostructured materials with these two types of iron (III) oxide nanoparticles will have very ignition, safety, and energy release properties. We are currently examining this hypothesis in our laboratory.

We believe that the intimacy of mixing between oxidizer and fuel is an important factor in the behavior of these materials. One problem, all nanomaterials suffer from, is the tendency for agglomeration into larger aggregates. In such a case the properties of the resulting composite 
may be influenced by the size of the aggregate and not the size of the individual nanoparticles, thus, defeating the potential benefit of the nanomaterial. Even though nanosized components are used, there is no guarantee that the sol-gel composite will have such mixing. To characterize this degree of mixing we have analyzed our nanostructured composite material using transmission electron microscopy (TEM) at LLNL. We have formulated a $\mathrm{Fe}_{2} \mathrm{O}_{3} / \mathrm{UFG} \mathrm{Al}$ material that is stoichiometric. Electron microscopy results for one such composite is shown in Figure 5.
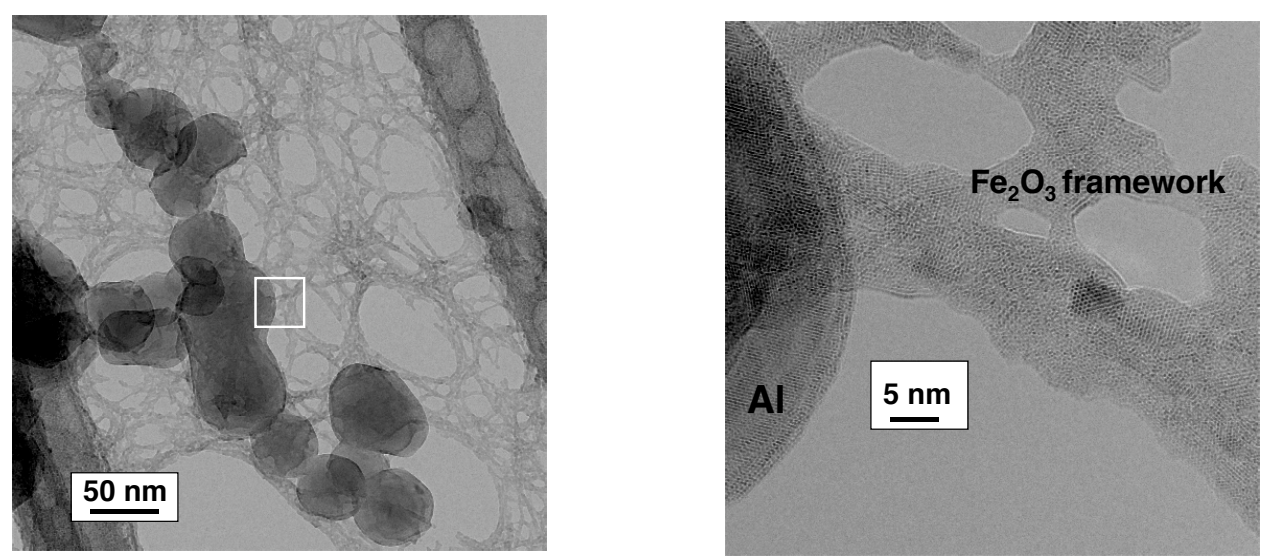

Figure 5. Transmission electron micrographs of sol-gel $\mathrm{Fe}_{2} \mathrm{O}_{3} / \mathrm{UFG} \mathrm{Al}$ nanocomposite.

In this figure the image on the right is a close up of the portion of the image on the left in the white box. In the images, the fibrous network is the iron (III) oxide phase and the spheres are the UFG Al. One can see the exquisite mixing between the constituent phases as well as the nanostructured nature of the composite. Here added particulate (UFG Al) phase is incorporated into the porous network of the skeletal iron (III) oxide phase. The demonstrated fine degree of mixing as well as the three-dimensional nanostructure of the composite may give these materials very important properties. We have performed additional physical and performance characterization on nanostructured energetic materials of this composition.

Some of the thermal properties of these materials have been investigated and contrasted with those of conventional sized ( $\square \mathrm{m}$-sized) thermites. Figure 6 contains the differential thermal analysis (DTA) traces for one energetic composites and one sol-gel nanostructured energetic. It is clear from these DTA traces that the thermal behavior of these materials is quite different. In the sol-gel xerogel $\mathrm{Fe}_{2} \mathrm{O}_{3} / \mathrm{UFG} \mathrm{Al}$ nanocomposite there are thermal events at $\sim 260, \sim 290$, and $\sim 590^{\circ} \mathrm{C}$. We have determined that the two lower temperature events are related to a phase transition and crystallization of the amorphous $\mathrm{Fe}_{2} \mathrm{O}_{3}$ phase. The exotherm at $\sim 590^{\circ} \mathrm{C}$ is the most interesting as it corresponds to the thermite reaction. This exotherm is very narrow and sharp, possibly indicating a very rapid reaction. Another point to be made here is that the thermite reaction takes place at a temperature markedly below the melt phase of bulk $\mathrm{Al}\left(\mathrm{T}_{\mathrm{m}}=660^{\circ} \mathrm{C}\right)$. This is very significant as in conventional thermite mixtures it is commonly thought that thermite reactions are initiated by the melting or decomposition of one of the constituent phases.[15] 

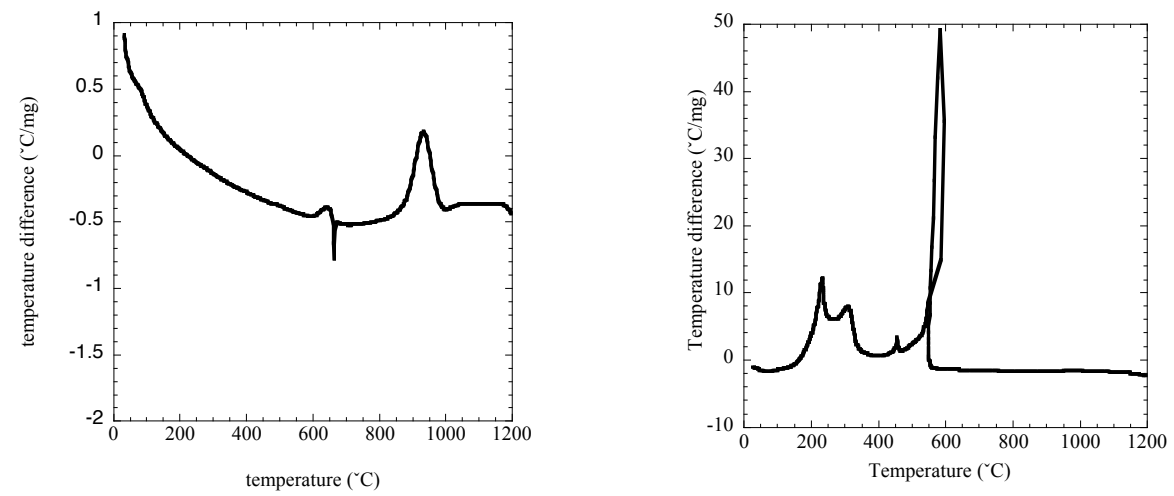

Figure 6. Differential thermal analysis traces of two thermite materials. The sample on the left is micron $\mathrm{Fe}_{2} \mathrm{O}_{3} / \mathrm{Al}(2 \square \mathrm{m})$ and the one on the right is sol-gel nanostructured xerogel $\mathrm{Fe}_{2} \mathrm{O}_{3} / \mathrm{UFG}$ Al.

Alternatively, the DTA trace of the dry powder mix of $\mathrm{Fe}_{2} \mathrm{O}_{3} / \mathrm{Al}$ commercial micronsized powders differs from that of the nanostructured material. There are no low temperature events in this DTA. This is not surprising, as the oxidizer in this mixture is crystalline $\mathrm{Fe}_{2} \mathrm{O}_{3}$ and not amorphous hydrous sol-gel iron (III) oxide. The main features of the trace occur at $\sim 660^{\circ} \mathrm{C}$ and $\sim 915^{\circ} \mathrm{C}$. The $660^{\circ} \mathrm{C}$ endotherm corresponds to the melting of the micron-sized $\mathrm{Al}$ and the $\sim 915^{\circ} \mathrm{C}$ exotherm is from the thermite reaction. In this case the thermite reaction takes place after the melting of Al. The ignition point of the traditional thermite material is $\sim 325^{\circ} \mathrm{C}$ higher than that for the nanocomposite. This peak is also much broader than that seen in the nanocomposite DTA and likely indicates a less rapid reaction. Although qualitative, the DTA analyses indicate that the thermal behavior of the sol-gel $\mathrm{Fe}_{2} \mathrm{O}_{3} / \mathrm{UFG} \mathrm{Al}$ and the conventional $\mathrm{Fe}_{2} \mathrm{O}_{3}$ composite are quite different. In addition, our phenomenological burn observations help support this contention as we have noted that the nanostructured energetics burn are much easier to ignite and burn much more rapidly than the conventional thermite composites.

To quantify such observations we have had the burn rates of our nanostructured energetic materials measured. This analysis was done at Texas Tech University by Professor Michelle Pantoya and co-workers. In these experiments loose powders of nanostructured aerogel and xerogel $\mathrm{Fe}_{2} \mathrm{O}_{3} / \mathrm{UFG} \mathrm{Al}$ were placed in an open-ended tube (confined geometry) and ignited with a $\mathrm{CO}_{2}$ laser. A high-speed camera (32,000 frames/sec.) was used to capture the ignition and propagation of the flame front. Burn velocities for selected samples of these materials were measured to be as high as $895 \mathrm{~m} / \mathrm{s}$ for the aerogel material and as high as $320 \mathrm{~m} / \mathrm{s}$ for the xerogel materials. These values are much higher than those for conventional thermite materials.[15] A full discussion of the burn rate results and analysis is forthcoming. Suffice it to say sol-gel nanostructured materials appear to have many of the interesting properties of energetic nanocomposites.

Small scale testing of energetic materials is done to determine their sensitivity to various stimuli including thermal degradation, friction impact and static spark. These characteristics are crucial as they often determine the necessary procedures employed in the synthesis, handling, storage, lifecycle, and processing of the material. Table 1 contains the small-scale safety test 
results for two of our sol-gel nanostructured energetic materials: aerogel $\mathrm{Fe}_{2} \mathrm{O}_{3} / \mathrm{UFG} \mathrm{Al}$ and xerogel $\mathrm{Fe}_{2} \mathrm{O}_{3} / \mathrm{UFG} \mathrm{Al}$.

Table 1. Summary of small-scale safety data for two sol-gel nanostructured energetic materials.

\begin{tabular}{|l|c|c|c|c|}
\hline Material Description & DH50 (cm) & Spark (\#/10 @ 1J) & B.A.M. Friction & $\begin{array}{c}\text { DSC Onset } \\
\left({ }^{\circ} \mathbf{C}\right)\end{array}$ \\
\hline aerogel $\mathrm{Fe}_{2} \mathrm{O}_{3} / \mathrm{UFG} \mathrm{Al}$ & 89 & $1 / 10 @ 0.03 \mathrm{~J}$ & $0 / 10 @ 36 \mathrm{~kg}$ & 190 \\
\hline xerogel $\mathrm{Fe}_{2} \mathrm{O}_{3} / \mathrm{UFG} \mathrm{Al}$ & 101 & $0 / 10 @ 1 \mathrm{~J}$ & $0 / 10 @ 36 \mathrm{~kg}$ & 233 \\
\hline
\end{tabular}

Both materials are sensitive to the drop hammer test. However, the values for the materials are relatively high and indicate that neither is especially sensitive to impact stimuli. This is not especially significant as thermites, in general are not especially impact sensitive. Neither of the two is friction sensitive and only the aerogel sample is spark sensitive. Please note that it is spark sensitive at a test energy of only $0.03 \mathrm{~J}$ whereas, the other material is not sensitive at $1 \mathrm{~J}$. In light of this result, we strongly recommend that when handling the aerogel $\mathrm{Fe}_{2} \mathrm{O}_{3} / \mathrm{UFG} \mathrm{Al}$ material procedures and conditions that minimize static electricity build up should be rigorously employed.

We found it interesting that aerogel composites are more sensitive to ignition than their xerogel counter parts. In fact, aerogel composites made are spark sensitivity in small-scale safety experiments and had significantly lower drop hammer $\left(\mathrm{DH}_{50}\right)$ values $(\sim 100 \mathrm{~cm}$ for xerogels and $\sim 90 \mathrm{~cm}$ for aerogel materials). More sensitive materials can be an advantage for certain applications but a disadvantage for safety concerns. We believe the reason for the difference in reactivity between the two materials has to do with their different thermal conductivities. The thermal conductivity of an aerogel is much lower than that of a xerogel of the same material.[7] Therefore, an aerogel composite will have a more difficult time dissipating a thermal stress than a xerogel composite. This results in the more rapid formation of "hot spots" in the aerogel material when it is thermally stressed by a spark or drop hammer. Once one of the hot spots reaches the ignition point the reaction is self-propagating and the entire composite is ignited.

Despite the above discussion, sol-gel methodology offers other advantages of safety and stability in energetic material processing. For example, ambient temperature gelation and low temperature drying schemes prevent degradation, and the water-like viscosity of the sol before gelation, allows easy casting to near net shapes, which is preferred over the alternative, hazardous machining.

Several other metal oxides undergo the thermite reaction. We have been developing solgel methods and utilizing known ones to prepare sol-gel nanostructured energetic materials with different compositions. The compositional versatility of the sol-gel method is one of its greatest attributes. A large number of inorganic metal oxidizers of particular interest to energetic materials applications are readily prepared using sol-gel methods. Figure 7 contains TEM images of two such oxides $\mathrm{MnO}_{2}$ and $\mathrm{SnO}_{2}$ made in our laboratory. 

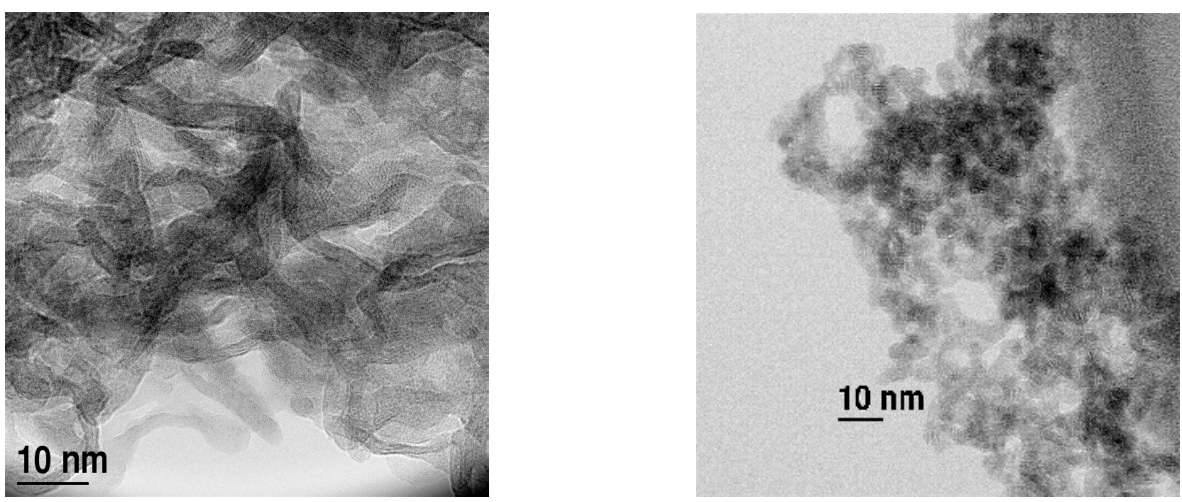

Figure 7. TEM image of sol-gel nanostructured $\mathrm{MnO}_{2}$ on the left and $\mathrm{SnO}_{2}$ on the right.

The images in Figure 7 clearly indicate that the materials are made up of a homogeneous distribution of interconnected particles with extremely small primary dimensions ( $\sim 5-10 \mathrm{~nm})$ with high surface areas. Both of these oxides undergo strongly exothermic thermite reactions with aluminum. Like the iron (III) oxide materials these solids can be prepared in a straightforward manner in a variety of safe and non-toxic solvents. It is also clear the materials have significant porosities. We have prepared and characterized thermitic nanostructured energetic materials with these oxides results of which will be reported elsewhere.

\section{Organic sol-gel nanocomposites}

In these types of composites we utilize organic sol-gel methods to produce a skeletal matrix of hydrocarbon fuel with oxidizer added in particulate form to fill the void spaces. This nanostructured material is unique from the thermite type materials, as it will generate significant amounts of gas upon decomposition. In this particular example, a solid skeleton of fuel based on resorcinol-formaldehyde has nanocrystalline ammonium perchlorate, the oxidizer, trapped within the pores. At optimum stoichiometry it has approximately the energy density of HMX.[9] Using a sol-gel procedure first described by Pekala to make aerogels, a porous organic solid matrix was prepared by the polycondensation of resorcinol with formaldehyde (RF).[14] Subsequent crystallization of an oxidizer, ammonium perchlorate (AP), within the pores of the gel matrix, completes the synthesis, followed by atmospheric drying of the wet composite to form a dense xerogel material. In our studies we have noted that atmospheric drying leads to the growth of large crystals of AP. Tappan et al. have reported that freeze drying of the wet composite material, to form cryogels. inhibits large crystal growth.[16]

To determine whether the material was energetic differential scanning calorimetry (DSC) was performed. DSC plots for a RF-AP nanocomposite and neat ammonium perchlorate are compared in Figure 8. The trace for the RF-AP nanocomposite on the right showed an exotherm at about $250^{\circ} \mathrm{C}$, indicating that it is indeed energetic. Pure AP has significantly less exothermicity and integrated decomposition enthalpy in the absence of the fuel gel skeleton (RF). It appears that the RF/AP composite undergoes decomposition via different pathway than pure AP 

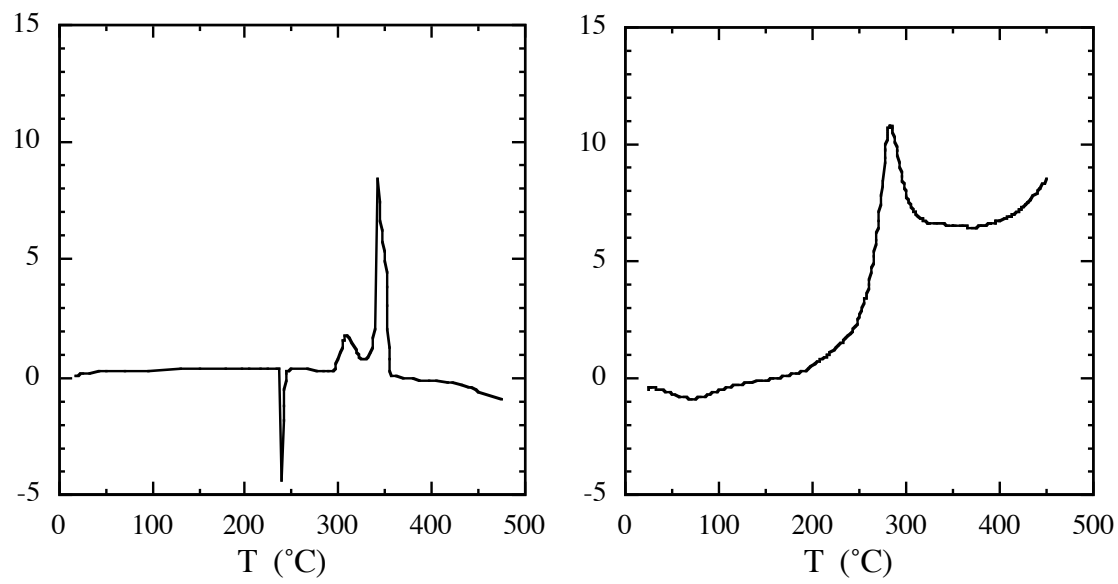

Figure 8. Differential scanning calorimetry scans for neat AP on the left and an RF/AP nanostructured energetic material on the right. The value on the y-axes is Heat flow (units: $\mathrm{W} / \mathrm{g})$.

\section{Summary and Conclusions}

We have described the use of sol-gel methodology in the synthesis and processing of nanostructured energetic materials in addition to the characterization of said materials. The solgel method provides a straightforward and practical route to a variety of nanostructured energetics materials with unique properties. We have demonstrated that using this method one can exercise suitable control over the particle size, morphology, porosity, surface area, and chemical composition. All of these factors are critically important in energetic materials performance. The method provides exquisite mixing of the constituent phases in a safe liquid medium. The materials produced are totally different than other energetic nanomaterials in that they are nanostructured. The material consists of an interconnected three-dimensional nanostructure where the second phase resides in the pore void volume of the first. We believe this nanostructure gives these materials unique properties relative to conventional composites and likely different than those of other energetic nanocomposites generated with alternative technologies.

The wide compositional variety of the sol-gel method affords the opportunity to tailor the form of energy output of the material, be it heat and light for the thermite reactions or heat and gas generation in the organic sol-gel case. These materials have been shown to have unique energy release properties relative to conventional composites. The versatility of the sol-gel methods allows products in a variety of materials forms. Thin films, monoliths, powders, sintered bodies, and coatings of sol-gel nanostructured energetic materials have been produced in our laboratory. Finally the methodology is compatible with current manufacturing technologies that may allow the mass production of precision energetic materials in the near future. 


\section{Acknowledgements}

The authors would like to acknowledge the efforts of Professor Michelle Pantoya and Mr. Keith Plantier both of Texas Tech University for burn rate measurements as well as Dr. Juergen Plitzko of LLNL for TEM analysis. This work was performed under the auspices of the U.S. Department of Energy by University of California Lawrence Livermore National Laboratory under contract No. W-7405-Eng8.

\section{References}

1. L.E Fried., W. M. Howard., P. C. Souers (1998) Cheetah 2.0 User's Manual Lawrence Livermore National Laboratory.

2. S.H. Fischer, M.C. Grubelich Proceedings of the 24th International Pyrotechnic Seminar 1998, U.S.A., 231-286.

3. M.E. Brown, , S.J. Taylor and M.J. Tribelhorn, Propellants, Explosives, and Pyrotechnics 1998, 23, 320-327.

4. A. Shimizu and J. Saitou, Solid State Ionics 1990, 38, 261-269.

5. S.F. Son, , B.W. Asay, J.R. Busse, B.S. Jorgensen, B. Bockmon, M. Pantoya, Proceedings of the $28^{\text {th }}$ International Pyrotechnic Seminar, 2001, Adelaide, Australia, November 4-9, 2001.

6. NANOMATERIALS: Synthesis, Properties, and Applications; Edlestein, A.S.; Cammarata, R.C. Eds.; Institute of Physics, Bristol U.K., 1996.

7. C.J. Brinker, G.W. Scherer Sol-Gel Science; Academic Press, Inc.: San Diego, CA, 1990.

8. Livage, J.; Henry, M.; Sanchez, C. Prog. Solid St. Chem. 1988, 18, 259.

9. Simpson, R.L.; Tillotson, T.M.; Satcher, J.H., Jr.; Hrubesh, L.W.; Gash, A.E. Proc. Int. Annu. Conf. ICT (3 $1^{\text {st }}$ Energetic Materials), Karlsruhe, Germany, June 27-30, 2000.

10. Gash, A.E.; Simpson, R. L.; Tillotson, T.M.; Satcher, J.H., Jr.; Hrubesh, L.W. Proc. $27^{\text {th }}$ Int. Pyrotech. Semin. Grand Junction, CO, July 15-21, 2000 p.41-53.

11. Tillotson, T.M.; Gash, A.E.; Simpson, R.L.; Hrubesh, L.W.; Thomas, I.M.; Poco, J.F. J. Non-Cryst. Solids 2001, 285, 338-345.

12. Gash, A.E.; Tillotson, T.M.; Satcher, J.H., Jr.; Poco, J.F.; Hrubesh, L.W.; Simpson, R.L. Chem. Mater. 2001, 13, 999.

13. Gash, A.E.; Satcher, J.H., Jr.; Simpson, R.L. Chem. Mater. 2003, 15, 3268.

14. Pekala, R.W. J. Mater. Sci., 1989, 24, 3321-3227.

15. Wang, L.L.; Munir, Z.A.; Maximov, Y.M. J. Mater. Sci. 1993, 28, 3693-3708.

16. B.C. Tappan, T. Brill Propellants, Explosives, and Pyrotechnics 2003, 28(2), 72. 
